\title{
LXVII. On the culture and preparation of hemp in dorsetshire, and on the growth of Sea Cale
}

\section{H.B. Way}

To cite this article: H.B. Way (1812) LXVII. On the culture and preparation of hemp in dorsetshire, and on the growth of Sea Cale, Philosophical Magazine Series 1, 39:170, 437-443, DOI: $10.1080 / 14786441208638162$

To link to this article: http://dx.doi.org/10.1080/14786441208638162

曲 Published online: 27 Jul 2009.

Submit your article to this journal $\lceil\pi$

Џ Article views: 2

Q View related articles $\square$ 


\section{$\left[\begin{array}{ll}437 & 1\end{array}\right.$}

LXVII. On the Culture and Preparation of Hemp in Dorsetshire, and on the Growth of Sea Cale*.

Dear Srr, As you informed me when you was lately in Dorsetshire, that the Society of Arts, \&c. were anxious to obtain information concerning the culture and preparation of hemp in this neighbourhood, I am induced to send you some accounts thereof.

I fear my memorandums on the subject will not be worthy the notice of the Society, and I should scarcely have ventured to bave put pen to paper upon it, if I had not uniformly found, that the persons who are concerned in the grow th and management of that article are shy of giving information. If what $J$ have sent should induce persons equal to the task, to make the needful inquiries in this county, Somerset, Suffolk and Norfolk, (which I believe to be the parts of England where hemp is most cultivated,) and make the culture more generally known than it now seems to be, I shall be much gratified. I hope, if you again visit this neighbourhood, to show you a very fine crop of wheat on the field where you last year saw the persons employed in collecting the male hemp; also another large field of exceeding good wheat, that produced hemp last year, neither of which have had any fresh manure upon them since the hemp was taken from the fields. I have added some observations on the growth of Sea Cale: this useful vegetable, growing naturally on some of the Cliffs near Bridport Harbour, and being one of the most valuable esculent plants that I know, I have found the culure of it in the kitchen garden more easy to manage than has been generally supposed.

I have sent different specimens of the seed, and some of the natural soil, for inspection; and remain, dear sir,

Your friend and obedient servant,

Bridport Harbour, March 1, 1811. H. B. WAX.

To C. Taylor, M.D. Sec.

\section{Account of the Culture anl Preparation of Hemp in} Dorsetshire.

Hemp is usually sown about the 15th of May, on the best arable land, on which about twenty cart loads of good

* From Tiansactions of the Society for the Encouragement of Arts, Manufactures, and Commerce, for $181 \mathrm{l}$. The thanks of the Society were voted to Mr. Way for this commusication. 
rotten dung has been spread, say about a ton to the load : this is well ploughed in, and the ground well ploughed two or three times, and well dragged and harrowed, to get the soil as fine as possible, and about two or two and a half bushels of seed sown to the acre; what produces no seed, called by some male or summer hemp, and by others cinner hemp, is drawn about five or six weeks after the plant comes up, it is at that time in blossom; when drawn, it is tied up in bundles, and carried to some meadow land, and there spread to ripen: when ripe and dry, it is bundled and stacked. What stands for seed has no flower that can be discovered; it is the female hemp, and is generally ripe early in Septenber, when it is drawn, bundled up, and stowed up in the field for the seed to dry and barden, when it is thrashed out in the fields. Most commonly in Dorset the seed is sold on the spot, at from 2s. 6d. to 7s. per bushel; an acre of hemp produces eighteen or twenty bushels. In Somerset they have sometimes thirty bushels of seed to the acre. In the sowing season I bave known $21 s$. per bushel paid for seed; when thrashed the hemp is carried to the meadows, and spread to ripen as the other, and stacked in the same way, to prepare it for sale; it is stent to the houses of the poor in the parishes round which it is raised, to be what is called scaled, that is, each separate stalk of hemp is broken in the hand, and the bemp, which is the outside rind or bark, is stripped off, in which state it is sent to market. The scaling is the emplovment of old men, women and children, and of the whole of the labouring family in the evening, as in winter they make but poor wages of it, and one principal inducement for them to do it is, that the wondy parts of the hemp make them a fire, but it soon burns out. Complaints are made of a great deal of the hemp being often wasted from improper management, and want of care in the scaling of it; at the Comptons and Bradford, a good deal more hemp would be raised if they could get it scaled, which they find much difficulty in doing; and if it were possible to construct a mill that would swingle it at a moderate expense, on some such plan as the flax swingling mills, and to afford some encouragement to the erecting them, as well as flax swingling mills, it would encourage the growth of both articles materially; an acre of hemp in a good season will produce,14, 16 or 18 weights, of 32 lbs. to the weight in Dorsetshire; in Somersetshire they reckon their weight two pounds less, and they sometimes get as much as 35 weights to the acre; the price of 
the weight of hemp is from $16 s$. to $20 s$, per weight. The rotation of crops as follow :

On ground well manured ..... Hemp.

Wheat.

Barley or Oats.

Clover with the above.

Wheat.

Barley or Oats.

Ground well manured........ Hemp.

But sometimes they dress the ground well for hemp every third year. The quantity of hemp sown in Dorset is very trifling in comparison to what is sown in Somerset. In the former it is chiefly confined to eight or nine parishes; whereas very large quantities are raised in Somerset, in the parishes of Misterton, Crewkerne, Hinton, St. George, Lopen, Seavingtons, Ilminster, Stocklinch, Donyatt, Kingstone, Shipton, Beauchamp, Barington, South Petherton, Martlock, Norton, Chiselborough, Stoke-under-ham, Monta-cute, Odcombe, the Chinniocks, the Cokers, the Comptons, Bradford, and a great many other parishes. Mr. Emanuel Pester, of Preston, near Yeovil, is in the middle of the hemp and flax county, and he can doubtless obtain and give every information that may be $\mathrm{u}$ ished on the subject, being so extensively engaged in agricultural pursuits himself, and so competent to give that sort of information wanted; a bounty of $3 d$. per stone on hemp, and $4 d$. per stone on flax, was for many years given by Government, but is now discontinued; it was paid by the Clerk of the Peace for the counties; and as the late $\mathrm{Mr}$. Wallace managed that for the county of Dorset uncommonly well, it is most probable that a very correct return for the colinty of Dorset could be obtained from the office of the Clerk of the Peace $f, r$ this county, of the quantity raised each year of both articles, during the continuance of the bounty; also from Devon and Somerset similar returns could be got. There are large quantities of h $\mathbf{m}$ p raised in Suffolk, the writer thinks, near St. Edmunds Bury and Stow market, in that count $\because$. He has been told they make linen so fine of hemp, as to be worth $5 s$. and $6 s$, per yard, and used for shirts in preference to Irish, being considered much more durable and better, so much so, as to induce the Irish to imitate the fabric, and stamp the cloth, Suffolk Hemp. It is also raised in Norfolk, in the neighbourhood of Lynn and Wisbeach, but it must be watered and prepared in some other way; indeed he is convinced that all the hemp imported from the Baltic is prepared differently from the mode used in Dorset and Somerset, 
Somerset, and must have been swingled before it was sent to the different ports it was shipped at for this country. The giving the former bounty on the growth, and increasing it on hemp and flax, would encourage the growth; but if given on the number of acres sown, the grower, as his ground would be in high order for a crop of turnips and wheat after, might be careless about his crop of hemp, as the bounty, to be worth notice, must be worth more than the value of the seed in common years and the labour of sowing.

Hemp in this county and the next is never sown in new grouud fresh broke up, but flax always by choice, when tresh ground can be got. Mr. John Pitfield is going to break up great part of the West Clift at Bridport Harbour, and sow it with flax this season. The writer, while on the subject of hemp, is led to mention, that when travelling in the year 1792, in the province of Massachusets near Boston, in North America, was assured that considerable quantities of hemp were raised in the township of Sunberry, about ten miles from Boston, and that it was always raised on the same ground every year, no other crop being sown in their hemp lands, and that it was manured every year, at the rate of about ten tons of manure to the acre of hemp. Respecting seed, he cannot learn that there is any for sale at Bridport, with the buyers who purchase it up for the growers at the hemp harvest, and he expects that very little can' be got from the growers round here. Somersetshire is a more likely place to get it, as he has known some of the hemp farmers to have upwards of an hundred acres of hemp in one season; round this they generally are only in a small way. A change of hemp seed is much wanted in Somerset and Dorset. Trials have been made two or three times to get it from Russia; but it is not possible to get new seed from the interior early enough in the fall at the shipping ports, and some old seed which has been shipped has not answered the purpose; if new could have been got, it would as generally have been used for a change, as the new Riga barrel flax seed is by the flax-growers. As the seed sown in Russia was considered a good sample, and its appearance much liked, possibly it might, at a future period, be obtained in the fall from Odesea, or some other port on the Black Sea, as it is understood that a good deal of hemp shipped at Riga and St. Petersburgh grows much nearer to the Black Sea than the Baltic; or possibly the seed of the Italian hemp raised in the neighbourhood of Bologna, or that of America, might be obtained in time to answer. Perhaps 
Perhaps tares, called by some vetches, might be cleared from the ground early enough for manuring and sowing the ensuing crop of hemp, and vetches might make it worth the farmer's attention: to this an objection was stated, which I do not just now remember. On talkiug with the gentleman before mentioned, and stating the American practice, with what had passed on it with my neighbours, he said, he had long been persuaded that it was a good practice, and that he had the last season a very gond crop of hemp on a piece of ground that had hemp the year before, and that he did not let the hemp stand for seed, but had it all down at the usual time for drawing the summer or male hemp, and the ground immediately sown with turnips, which were fedoff with sheep, and the ground then slighily manured, and hemp sown again at the proper season; and that he had then, October 27, 1808, a piece of turnips after his hemp, which were worth $6 l$. per acre. It is to be observed, that the acre here meant is the British acre of one hundred square poles, three hundred and four square yards each. The manure mostly used for hemp is good rotten stable dung, which is much preferred to any other, though lime is frequently used; but manufacturers pretend to assert, (with what foundation I cannot say,) that they can distinguish a material difference in the quality of the hemp, where lime has been used instead of dung, as from lime they say hemp is more harsh and brittle, and not of such a soft silky quality as where dung has been used. The writer has endeavoured to throw together every thing that occurs to him on the sulject of the cirlture of hemp, which, from being born and residing great part of his life in a part of the county where it has been extensively cultivated for ages, he bas been able to collect; but where it is not very easy to obtain direct information, as both the growers and manufacturers are very shy of giving any, under an idea that it might injure their own interest by assisting to extend the cullure to other countries. He believes that his statement may be depended upon; but he is no farmer, and therefore the loose hints thrown together here on the subject may not be so clearly and satisfactorily explained as he could wish; but if they in the smallest degree assist in encouraging the growth of an arlicle so essential to the welware and prosperity of the kingdom, it will afford him the most hearifelt pleasure.

H. B. WAY.

Vol. 39. No. 170. June 1812. 
Account of the Culture of Sea-Cale, or Sea-Kale.

THE mode which I consider the best for the culture of sea-cale, is to draw lines in a very dry soil and dry situation, on ground with a southern aspect, about two feet one way by about eighteen inches the other, and where the lines cross to put in three or four good perfect seeds in a square or triangle, about three inches apart; this may be done any time in November or December in open weather, and it will require no other care afterwards but keeping the ground clear from weeds till the autumn of the following year, when all the plants but one of the finest in each square may be taken up, which if wanted will serve to form other beds set the same distance apart. The ground in the intervals of the plants should be dug in the spring and fall of the year, taking care not to injure the plants. The leaves should be left on the plants till they fall off naturally, which will not in general be sooner than the latter end of November. In the autumn of the second year the same attention should be paid to the plants, and to remove the dead leaves.

In the third year, about the middle or latter end of November, when the leaves have been cleared away, and the ground dug, each plant should be covered over close with a tub, pan, a heap of small stones, coarse cinders, or coarse bark, raised about ten or twelve inches over the crown of each plant, and from about the latter end of February to the latter end of March the plants will be very fine and fit for use. I prefer that which has been bleached with our round sea-gravel, about the size of Jarge peas or beans, to any other mode whatever. The plants sbould be cut but once in a year, as cutting it oftener weakens and lessens the size of the plants. If it is not desired to have the plants large, they may be bleached and cut a year sooner.

I have sent a specimen of the sandy soil in which it grows naturally bere, as I think the generality of gardeners are too careful, and mantre the ground too highly for it. In the month of April last, after cutting my plants, I covered the ground all over, at least six inches above the crown of the plants, with this earth : they soon shot up through it, and never looked finer or produced a larger quantity of good seed than that year.

I am thus particular in order to show that this vegetable will succeed as well, if not better in poor ground than in rich, provided the soil be dry, and care taken in the management; I speak from long experience, having been well acquainted with the management of this valuable plant from 
my youth. When I cut the sea-cale for use, I immediately draw up the earth with a trowel, so as completely to cover the whole of the plant; this I fancy makes them grow more luxuriantly. This plant, if properly managed, is superior to asparagus, and if more is cut than wanted for immediate use, it will keep for some days in a pan of cold water, but of course it cannot be better than when recently cut. It precedes the use of asparagus, being ready for the table in February and March.

H. B. WAY.

LXVIII. On a gaseous Compound of carbonic Oxide and Chlorine. By John Davy, Esq. Communicated by Sir Humphry Davy, Knt. LL.D.Sec. R.S.*

Srace the influence of electricity and solar light, as chemical agents, are analogous in many respects, and as the former produces no change in a mixture of carbonic oxide and chlorine, it was natural to infer the same respecting the latter.' MM. Gay Lussac and Thenard assert that this is the case ; they say that they have exposed a mixture of carbonic oxide and chlorine, under all circumstances, to light, without observing any alteration to take place $\uparrow$. Mr. Murray has made a similar statement $¥$.

Having been led to repeat this experiment, from some objections made by the last-mentioned gentleman to the theory of my brother, Sir Humphry Davy, concerning chlorine, I was surprised at witnessing a different result.

The mixture exposed, consisted of about equal volumes of chlorine and carbonic oxide; the gasses had been previously dried over mercury by the action of fused muriate of lime, and the exhausted glass globe into which they were introduced from a receiver with suitable stopcocks, was carefully dried. After exposure for about a quarter of an hour to bright sunshine, the colour of the chlorine had entirely disappeared; the stopcock belonging to the globe being turned in mercury recently boiled, a considerable absorption took place, just equal to one half the volume of the mixture, and the residual gas possessed properties perfectly distinct from those belonging either to carbonic oxide or chlorine.

Thrown into the atmosphere, it did not fume. Its odour

* From the Philosophical Transactions for 1812, part i.

+ Recherches Physico-Chimiques, tom.ii. p. 150.

Nicholson's Journal, vol. xxx. p. 227.

F $f 2$ 